\title{
Analisis Perbedaan Peformance dan Quality Of Service (Qos) Antara Eigrp dengan Ospf (Studi Kasus Menggunakan 6 Router Melalui GNS 3 dan Wireshark)
}

\author{
Unung Verawardina \\ Program Studi Pendidikan Teknologi Informasi dan Komputer IKIP-PGRI Pontianak Pontianak, Indonesia
}

\author{
A R T I C L E I N F O \\ Article history: \\ Received 21 November \\ 2017 \\ Received in revised form \\ 12 Desember 2017 \\ Accepted 15 Januari 2018 \\ Available online 25 \\ Februari 2018 \\ Kata Kunci: \\ EIGRP, OSPF, Peformance, \\ Quality Of Service (Qos) \\ Keywords: \\ EIGRP, OSPF, Peformance, \\ Quality Of Service (Qos)
}

\begin{abstract}
A B S T R A K
Dalam pengaturan routing dinamis diperlukan sebuah routing protokol untuk melakukan pengaturan mencari jalur yang tersingkat dan terbaik. Routing protokol ada dua jenis yaitu distance vektor dan link state. Penggunaan routing EIGRP yang mencakup distance vektor dan link state sedangkan OSPF mencakup link state, keduanya dianggap baik untuk di implementasikan dalam jaringan yang kompleks karena dapat beradaptasi dengan baik apabila terjadi perubahan pada router. Dalam penelitian ini dilakukannya metode eksperimen melalui percobaan simulasi routing dinamis menggunakan 6 router dengan routing EIGRP dan OSPF melalui simulator GNS3 dan aplikasi wireshark, kemudian menganalisis perbedaan peformance dengan membandingkan tabel routing dan kecepatan waktu tranfer data yang diterima routing EIGRP dan routing OSPF. Sementara untuk Quality of Service (QoS) membandingkan kualitas layanan jaringan dari routing EIGRP dan OSPF yang meliputi delay, packet loss, dan throughput. Berdasarkan hasil penelitian menunjukkan bahwa tabel routing EIGRP lebih baik dalam pemilihan jalur, EIGRP lebih kecil waktu tansfer data maka perpindahan data nya lebih cepat dibandingakan OSPF. Secara keseluruhan Quality Of Service (Qos) delay, packetloss dan throughput pada EIGRP dan OSPF seimbang dan baik.
\end{abstract}

\section{A B S T R A C T}

In a dynamic routing setting a routing protocol is required to perform the settings to find the shortest and best path. Routing protocols are of two types: vector distance and link state. Use of EIGRP routing that includes long-range vectors and link state OSPF Link link state coverage, peg well to be implemented in complex network because it can adapt well. In this research is the method used for routing and speed of time available EIGRP routing and OSPF routing through simulator GNS3 and wireshark application, then analyze the difference of peformance with speed of routing table and speed of time. While for Quality of Service (QoS) compare network service quality from EIGRP and OSPF routing which include delay, packet loss, and throughput. Based on the results of the research shows the EIGRP routing table is better in the selection path, EIGRP smaller time tansfer data then its data transfer faster than the OSPF. Overall Quality Of Service (Qos) delay, packetloss and throughput on EIGRP and OSPF are well balanced and good.

\footnotetext{
* Corresponding author.

E-mail addresses: unungverawardina@gmail.com (Unung Verawardina)
} 


\section{Pendahuluan}

Perkembangan teknologi di era saat ini semakin berkembang pesat, sama halnya dengan perkembangan jaringan komputer. Dengan peran teknologi dapat menyampaikan informasi semakain cepat, berkomunikasi tanpa dibatasi oleh jarak, ruaang dan waktu. Secara umum jaringan komputer adalah komputer yang saling terhubung satu sama lain secara global, dengan jaringan komputer kita dapat melakukan pertukaran data. Menurut (Munir, 2009) jaringan komputer (computer network) adalah hubungan dua buah komputer atau lebih yang dapat saling terkoneksi satu dengan yang lain, tujuan utama adalah untuk melakukan pertukaran data. Adanya jaringan komputer kita dapat saling bertukar informasi berbagi sumber daya, dapat saling berkomunikasi antara pengguna satu dengan lainnya dan mengakses informasi.

Untuk mendesain jaringan diperlukan tata cara dan topologi jaringan yang sesuai kebutuhan. Topologi jaringan yakni menggambarkan struktur desain jaringan. Bentuk topologi jaringan seperti ring, star, tree, bus, mesh dan wireless (nirkabel). Selain itu juga dibutuhkan perlatan pendukung dalam membuat jaringan yakni router. Router adalah sebuah alat yang dapat menghubungkan dua atau lebih jaringan, untuk menghubungkan beberapa jaringan tersebut dibutuhkan sebuah routing. Router memiliki peran penting dalam suatu jaringan, maka dari itu perlu untuk dipahami.

Routing disini mengacu pada proses pemilihan rute atau jalur yang dilewati untuk pengiriman paket-paket dan meneruskan paket tersebut ke jaringan yang dituju. Adapun jenis routing terdiri dari routing statis dan dinamis. Routing statis adalah metode routing nya dalam mengirimkan paket-paket di lakukan secara manual oleh administrator. Sedangkan routing dinamis routingnya dilakukan secara otomatis dengan bantuan aplikasi jaringan. Penggunaan routing dinamis akan lebih memudahkan dalam hal proses, kapasitas dan manajemen routing dari pada routing statis. Di dalam teknologi jaringan pada saat ingin melakukan pengiriman data dengan routing dinamis maka ada sebuah routing protokol yang berfungsi untuk mengatur rute jaringan. Routing dinamis EIGRP (Enhanced Interior Gateway Routing Protocol) adalah routing protokol yang mengunakan protokol distance vektor dan link state. Sedangkan routing dinamis OSPF (Open Short Path First) adalah routing protokol yang menggunakan protokol link state.

Administrator jaringan penting untuk mengetahui perbedaan peformance/kinerja dari suatu routing sehingga dapat merancang layanan jaringan yang berkaulitas.

Pada penelitian ini dilakukannya simulasi routing dinamis menggunakan EIGRP dan OSPF menggunakan simulator GNS3 dan Wireshark untuk melakukan analisis. Adapun tujuannya untuk mengetahui perbedaan peformance/kinerja dari suatu routing tersebut mulai dari kecepatan, transfer data, traceroute dan Quality of Service (QoS) yaitu kualitas layanan pada jaringan yang meliputi delay, packet loss, dan throughput

\section{Metode}

Metodologi penelitian yang digunakan adalah eksperimen dengan melakukan percobaan menggunakan routing protokol EIGRP dan OSPF. Adapun skenario percobaan sebagai berikut:

1. Menggunakan 6 router melalui simulator GNS3 dan Wireshark.

2. Simulasi pengiriman paket data, dengan jalur percobaan. Simulasi pengiriman paket dapat dilihat pada Tabel 1 dibawah ini.

Tabel 1. Pengiriman Paket Data

\begin{tabular}{ll}
\hline Pengiriman Jalur & Paket Data \\
\hline Router1 ke Router2 \\
Router1 ke Router3 \\
Router2 ke Router1 \\
Router2 ke Router3 \\
Router2 ke Router5 \\
Router3 ke Router1 \\
Router3 ke Router2 \\
Router3 ke Router4 \\
\hline
\end{tabular}




\section{Router4 ke Router3 \\ Router4 ke Router5 \\ Router4 ke Router6 \\ Router5 ke Router2 \\ Router5 ke Router4 \\ Router5 ke Router6 \\ Router6 ke Router4 \\ Router6 ke Router5}

3. Menggunakan laptop dengan kecepatan prosessor core 3.

4. Melakukan analisis perbedaan peformance meliputi pengujian perintah "ping", "routing table" dan "traceroute" dan Quality Of Service.

\section{Hasil dan pembahasan}

Percobaan simulasi ini menggunakan aplikasi GNS3 untuk membuat jaringan routing EIGRP dan OSPF, sedangkan untuk melakukan analisis menggunakan bantuan aplikasi wireshark untuk menganalisis delay, packet loss, dan throughput.

\section{a. Konfigurasi Jaringan}

Penelitian dimulai dengan membuat topologi jaringan router sebanyak 6 router, kemudian mengkonfigurasikan masing-masing IP address. Mulai dari Router_1 IP address 192.168.10.1 sampai Router_6 IP address 192.168.17.2. Sebagai berikut:

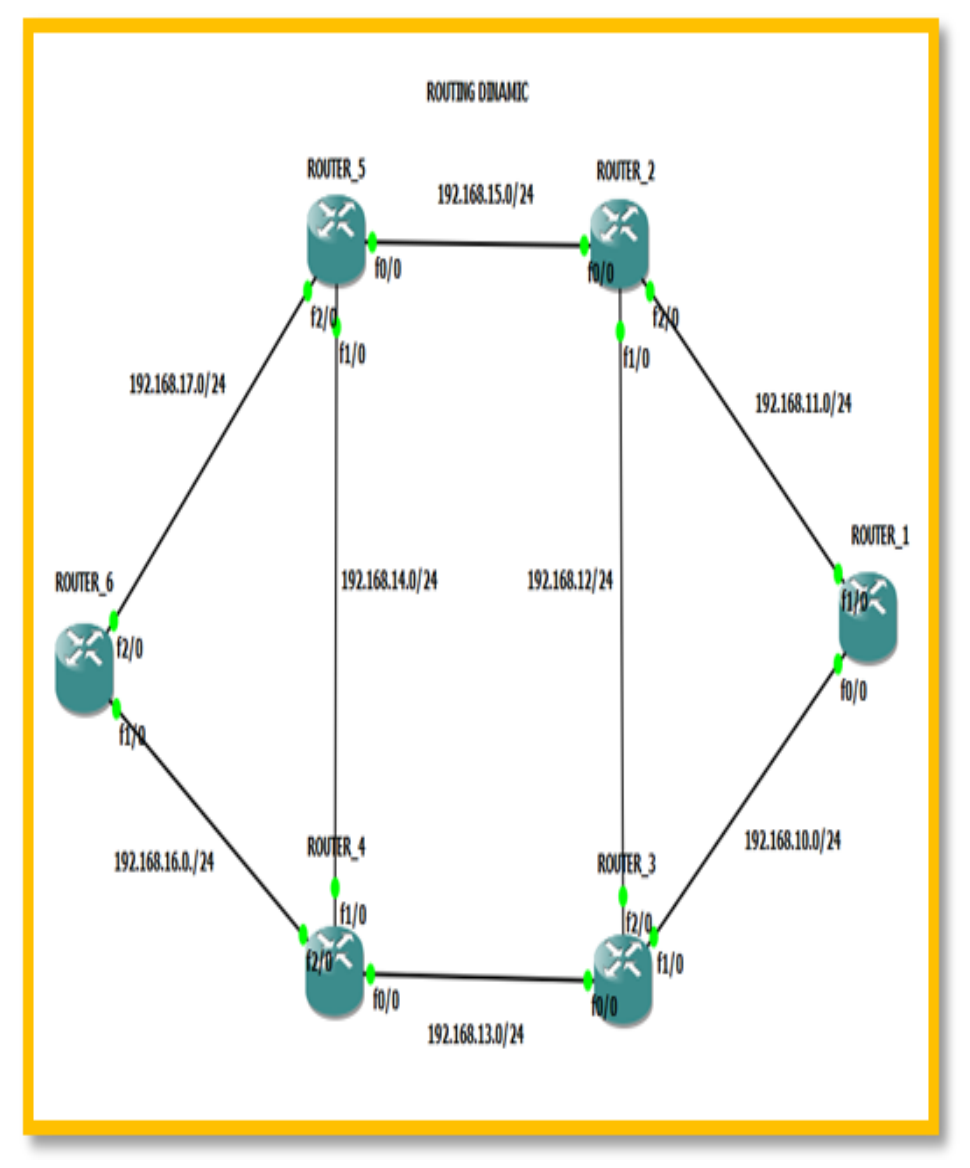

Gambar 1 Topologi Jaringan 


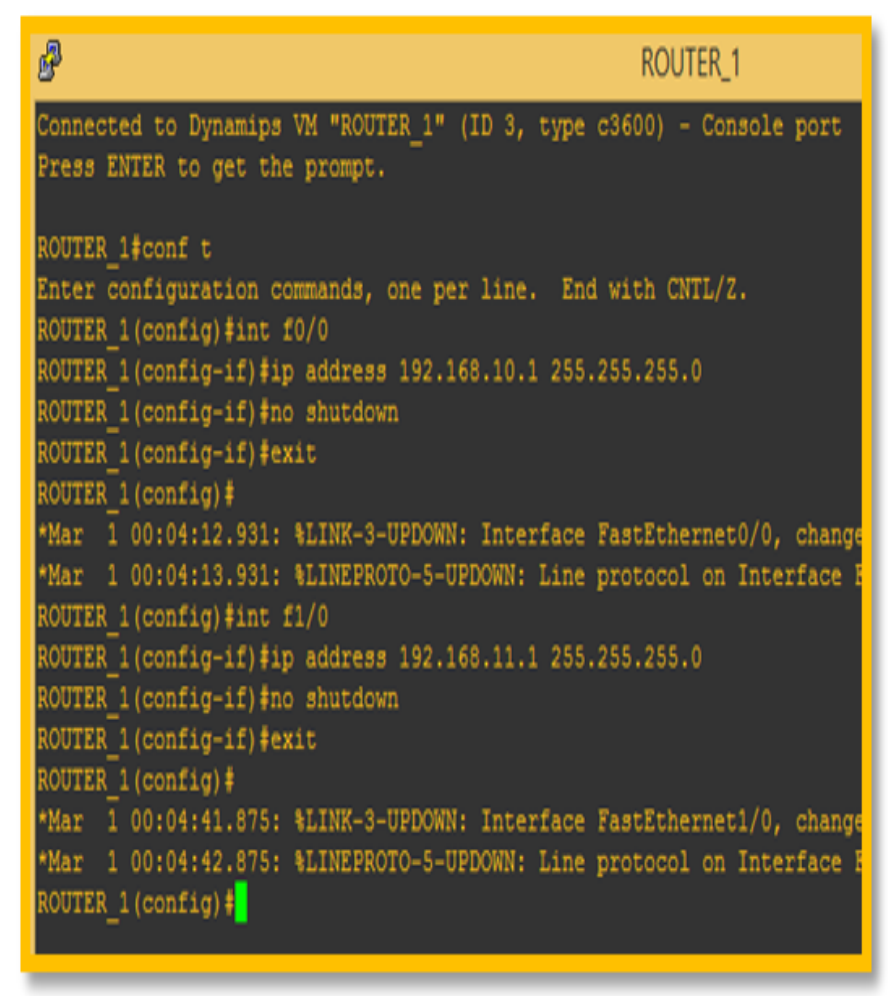

Gambar 2. Contoh Konfigurasi IP addres

Selanjunya melakukan konfigurasi routing protokol dengan perintah EIGRP disetiap masing masing router.

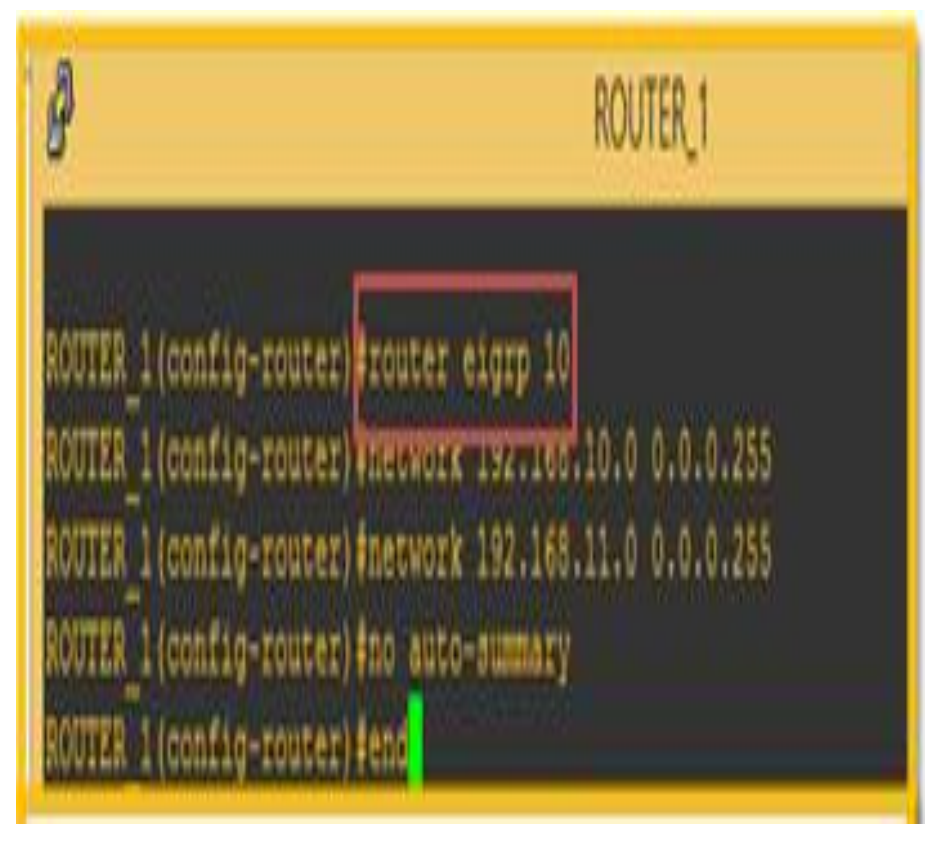

Gambar 3. Contoh Routing EIGRP

Untuk konfigurasi routing protokol dengan perintah OSPF di setiap masing masing router sebagai berikut: 


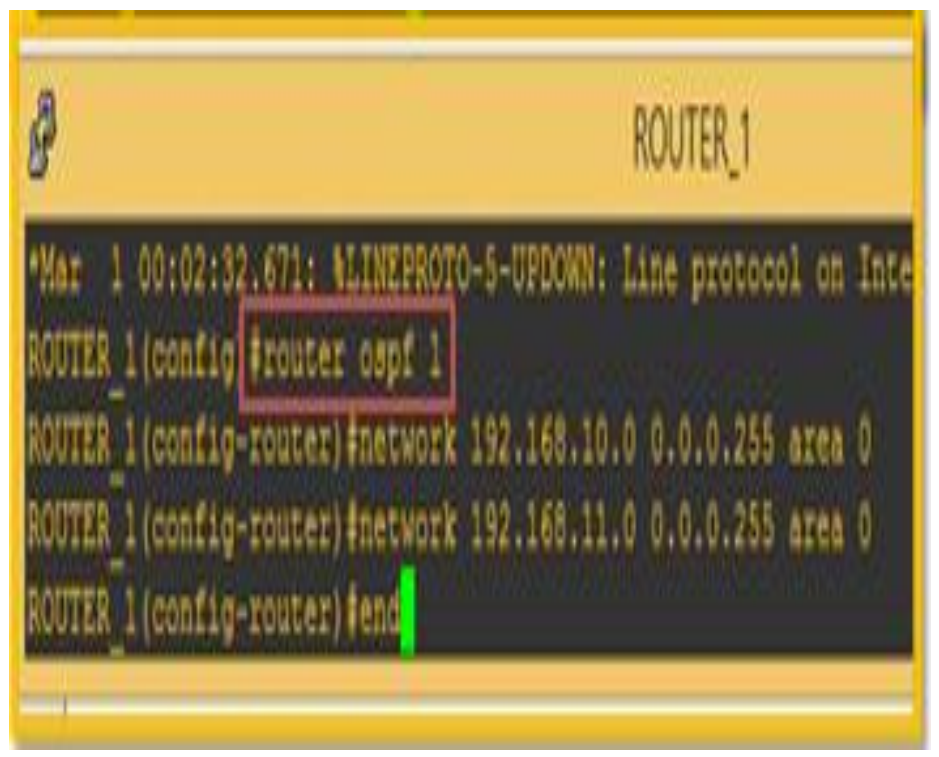

Gambar 4. Contoh Routing OSPF

\section{b. Perintah Ping EIGRP dan OSPF}

Pada tahap ini dilakukanya pengujian koneksi antar router menggunakan perintah ping.

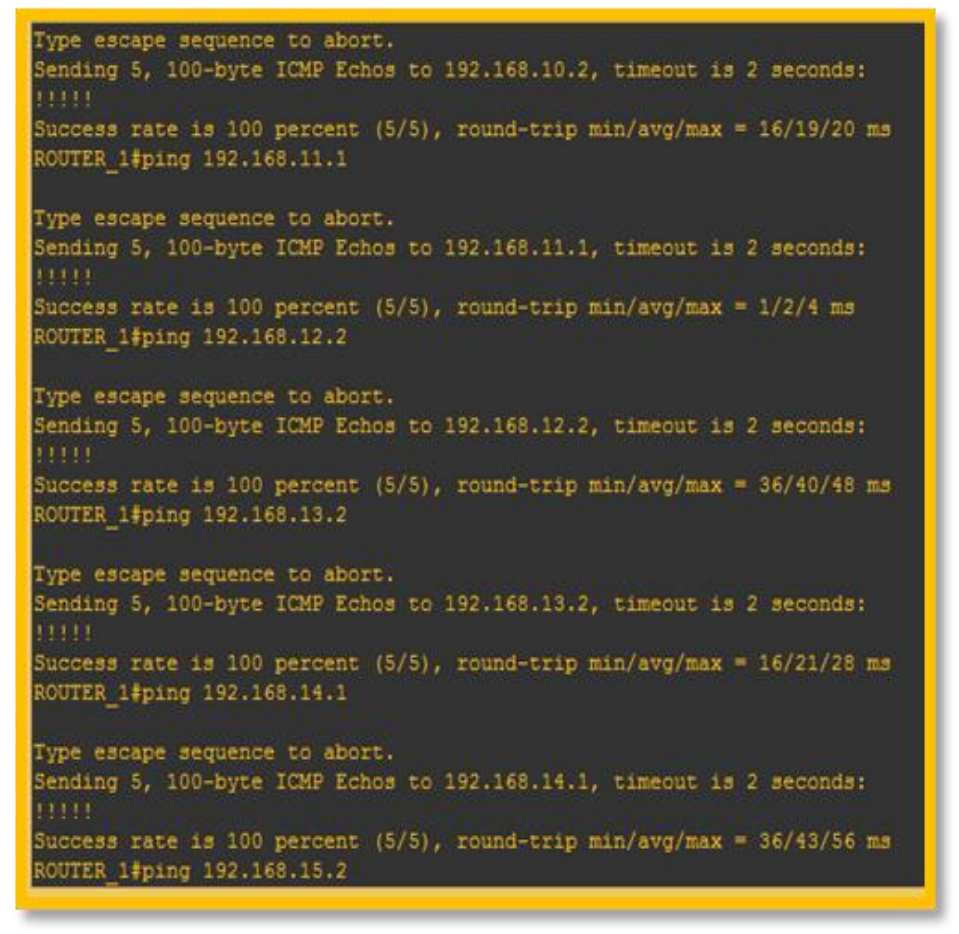

Gambar 5. Perintah Ping

Berdasarkan hasil pengujian pada gambar 5, terbukti bahwa konfigurasi routing pada EIGRP dan OSPF sukses terkoneksi semua routernya dengan rate $100 \%$ dan dengan kecepatan yang berbeda-beda.

\section{c. Routing Table EIGRP dan OSPF}

Berdasarkan hasil pengujian show ip route di ketahui hasil tabel routing pada EIGRP dan OSPF sebagai berikut: 


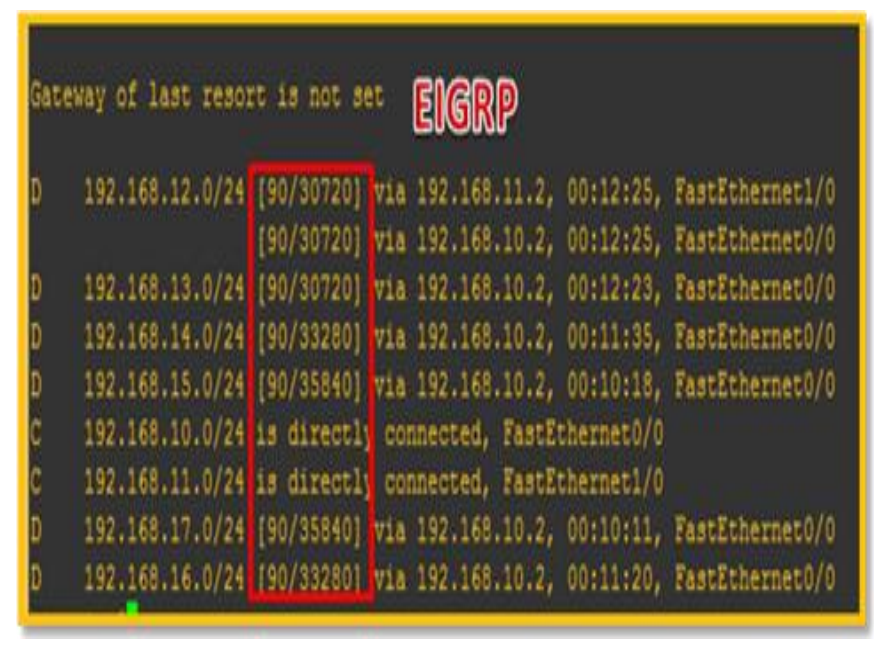

Gambar 6. Perintah Show ip route EIGRP

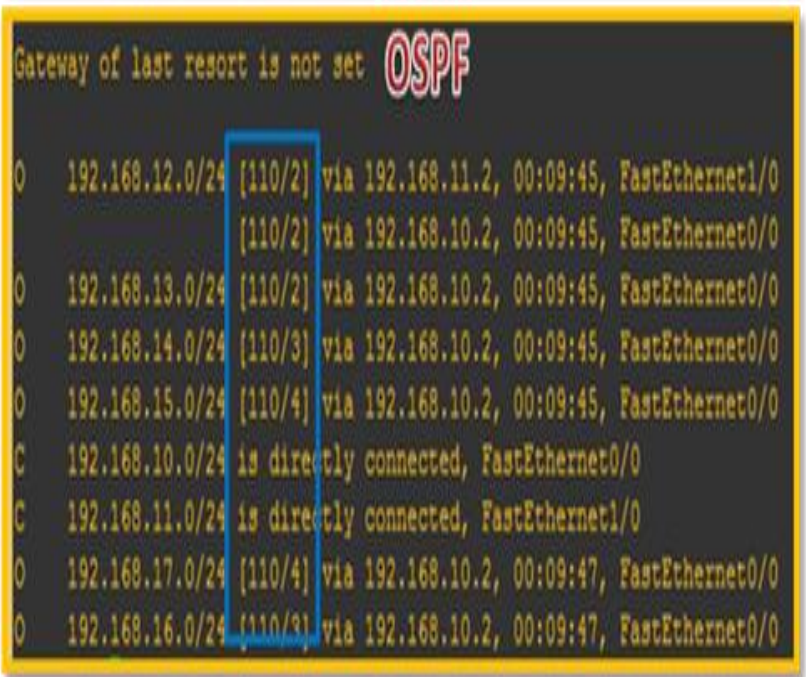

Gambar 7.Perintah Show ip route OSPF

Berdasrkan gambar 6 dan 7, pada tabel routing diperoleh angka 90/30720 pada EIGRP dan 110/2 pada OSPF. Adapun Angka 90 dan 110 adalah nilai Administrative Distance (AD) untuk menentukan routing protocol. Angka 30720 pada EIGRP dan 2 pada OSPF adalah nilai (Metric) ialah suatu ukurang untuk menentukan nilai cost untuk menuju network tujuan. Berdasarkan tabel routing EIGRP dan OSPF nilai AD dan matric yang lebih kecil adalah EIGRP oleh karena itu matric EIGRP lebih baik dalam dalam pemilihan jalur.

\section{d. Traceroute EIGRP dan OSPF}

Penggunaan perintah traceroute dalam percobaan ini ialah sebagai perintah untuk melihat jalur akses router yang digunakan untuk loncatan (hops) ke lokasi alamat yang dituju, serta waktu yang dibutuhkan. 


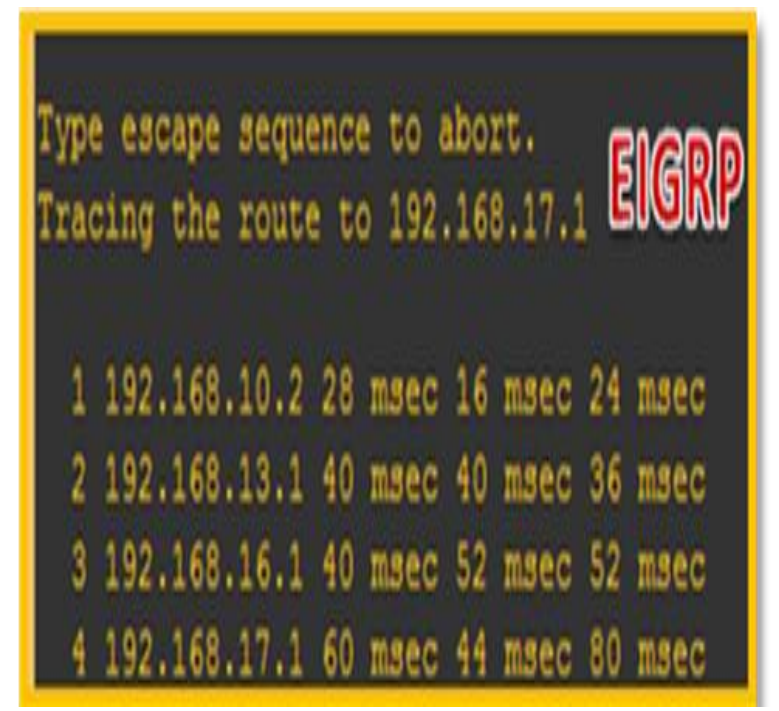

Gambar 8. Traceroute EIGRP

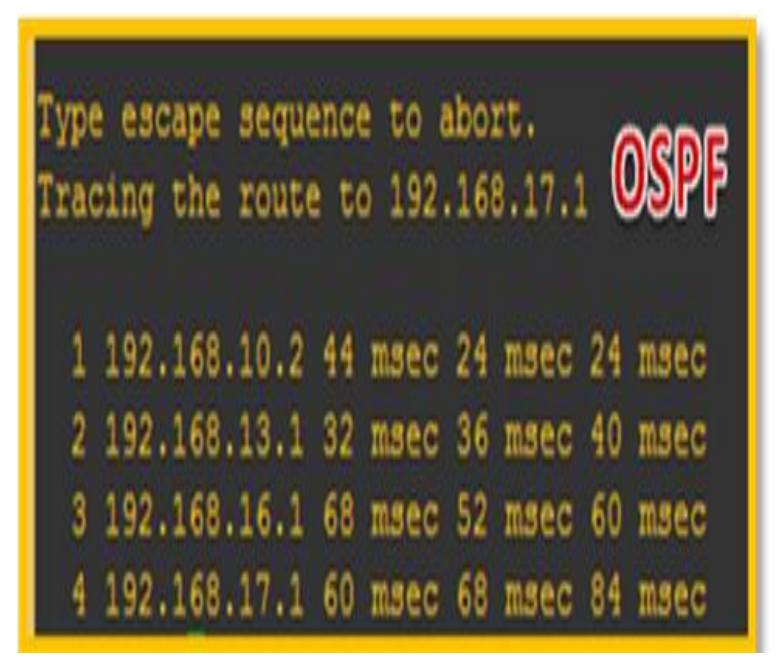

Gambar 9. Traceroute OSPF

Berdasarkan hasil traceroute pada gambar 8 dan gambar 9, menunjukan bahwa router 1 ke Router 6 melalui router, 3,4, dan 5 (hops), ini berarti melalui 3 hops. Sedangkan waktu pengiriman paket dari Router_1 ke Router_6 melalui 3 hops dengan routing protokol EIGRP adalah $80 \mathrm{~ms}$ dan routing protokol OSPF adalah $84 \mathrm{~ms}$, untuk tranfer paket data semakin kecil waktu perpindahan data maka semakin cepat. Sedangkan rata-rata waktu yang digunakan dengan traceroute sebanyak 5 kali percobaan di peroleh ratarata nilai EIGRP adalah 73,6 ms dan OSPF adalah 76,8 ms.

\section{e. Quality Of Service (Qos)}

Dalam penelitian ini Quality of Service (Qos) yang diamati dibatasi meliputi delay, pakte loss, dan throghput. Adapun analisis yang dilakukan menggunakan aplikasi wireshark.

\section{f. Delay}

Delay dalam percobaan ini adalah untuk mengetahui waktu tunda pada paket yang dikirimkan. Adapun delay terjadi di pengaruhi beberapa faktor misalnya proses tranmisi, jarak, media fisik dan sebgainya.

Menurut (Putri,dkk, 2014) adapun perhitungan mencari delay:

$$
\frac{\text { Rata - rata Delay }=}{\text { Total waktu }}
$$




\section{g. Packet Loss}

Packet loss dalam percobaan ini diartikan sebagai total paket yang hilang. tingkat packet loss di lihat dalam persen (\%).Beberapa faktor penyebab terjadinya packet loss seperti memory yang melebihi kapasitas node, antrian dalam jaringan, collision dan congestion.

Menurut (Ferguson, \& Huston, 1998) adapun perhitungan mencari packet loss:

PacketLoss $=\frac{\text { Data yang dikirim }- \text { data yang diterima }}{\text { Paket data yang dikinim }} \times 100 \%$

\section{h. Throughput}

Throughput, dalam percobaan ini adalah waktu paket data yang dikirim dan diamati dalam waktu tertentu yang diukur dalam bps.

Menurut (Resnu, 2015) adapun perhitunganmencari throughput:

Throughput $=\frac{\text { Jumlah data yang dikirim }}{\text { Waktu pengiriman data }}$

Adapun hasil analisis perhitungan Quality of Service (Qos) terdiri dari delay, packetloss dan throughtput pada routing EIGRP dan OSPF menggunakan aplikasi wireshark, dapat dilihat pada table 2 hasil Quality Of Service (Qos) pada EIGRP, dan pada table 3 hasil Quality Of Service (Qos) pada OSPF, sebagai berikut:

Tabel 2. Hasil Quality Of Service (Qos) Pada EIGRP

\begin{tabular}{rccc}
\hline Percobaan & $\begin{array}{c}\text { Delay } \\
\text { (ms) }\end{array}$ & $\begin{array}{c}\text { Packet } \\
\text { Loss (\%) }\end{array}$ & $\begin{array}{c}\text { Througput } \\
\text { (kbit/s) }\end{array}$ \\
\hline Router1 ke Router2 & 1,24 & 0,71 & 77,51 \\
Router1 ke Router3 & 1,45 & 0,71 & 55 \\
Router2 ke Router1 & 1,48 & 0,70 & 56,59 \\
Router2 ke Router3 & 1,33 & 0,72 & 63,65 \\
Router2 ke Router5 & 1,47 & 0,71 & 56,03 \\
Router3 ke Router1 & 0,97 & 0,69 & 82,42 \\
Router3 ke Router2 & 1,42 & 0,69 & 54,30 \\
Router3 ke Router4 & 1,37 & 0,68 & 56,43 \\
Router4 ke Router3 & 1,47 & 0,73 & 58,11 \\
Router4 ke Router5 & 1.50 & 0,71 & 55,16 \\
Router4 ke Router6 & 1,49 & 0,12 & 55,82 \\
Router5 ke Router2 & 2,84 & 0,70 & 29,72 \\
Router5 ke Router4 & 1,48 & 0,67 & 55,93 \\
Router5 ke Router6 & 1,45 & 0,70 & 56,52 \\
Router6 ke Router4 & 1,41 & 0,69 & 61,59 \\
Router6 ke Router5 & 1,45 & 0,66 & 58,02 \\
\hline
\end{tabular}

Berdasarkan tabel 2 hasil Quality of Service (Qos) pada EIGRP, dilakukanya percobaan menggunakan 6 router, dengan memiliki 16 jalur pengiriman paket data. Diketahui nilai delay terendah $0,97 \mathrm{~ms}$ dan tertinggi 2,84 ms. Untuk packet loss terendah $0,12 \%$ dan tertinggi $0,72 \%$, serta throughput terendah $29,72 \mathrm{kbit} / \mathrm{s}$ dan tertinggi $82,4 \mathrm{kbit} / \mathrm{s}$.

Tabel 3 Hasil Quality Of Service (Qos) Pada OSPF

\begin{tabular}{lccc}
\hline Percobaan & $\begin{array}{c}\text { Delay } \\
(\mathrm{ms})\end{array}$ & $\begin{array}{c}\text { Packet } \\
\text { Loss }\end{array}$ & $\begin{array}{c}\text { Througput } \\
(\mathrm{kbit} / \mathrm{s})\end{array}$ \\
& & $(\%)$ & \\
Router1 ke Router2 & 2,27 & 0,52 & 42,06 \\
Router1 ke Router3 & 1,89 & 0,53 & 47,02 \\
Router2 ke Router1 & 2,23 & 0,55 & 43,26 \\
\hline
\end{tabular}




\begin{tabular}{lccc}
\hline Router2 ke Router3 & 2,25 & 0,57 & 42,84 \\
Router2 ke Router5 & 4,52 & 0,54 & 21,06 \\
Router3 ke Router1 & 1,91 & 0,59 & 55,45 \\
Router3 ke Router2 & 2 & 0,62 & 49,06 \\
Router3 ke Router4 & 2,05 & 0,54 & 45,23 \\
Router4 ke Router3 & 2,16 & 0,52 & 46,87 \\
Router4 ke Router5 & 2,23 & 0,53 & 44,63 \\
Router4 ke Router6 & 2,1 & 0,57 & 46,46 \\
Router5 ke Router2 & 4,59 & 0,54 & 22,06 \\
Router5 ke Router4 & 1,73 & 0,52 & 60,02 \\
Router5 ke Router6 & 2,07 & 0,57 & 49,98 \\
Router6 ke Router4 & 2,24 & 0,56 & 44,16 \\
Router6 ke Router5 & 1,94 & 0,61 & 51,06 \\
\hline
\end{tabular}

Berdasarkan tabel 3 hasil Quality Of Service (Qos) pada OSPF. Dilakukanya percobaan menggunakan 6 router, dengan memiliki 16 jalur pengiriman paket data. Diketahui nilai delay terendah 1,73ms dan tertinggi 4,59 ms. Untuk packet loss terendah $0,52 \%$ dan tertinggi $0,61 \%$, serta throughput terendah $21,06 \mathrm{kbit} / \mathrm{s}$ dan tertinggi 51,06kbit/s.

Disimpulkan berdasarkan tabel 2 dan tabel 3, hasil Quality Of Service (Qos) pada EIGRP dan OSPF diketahui nilai delay masih tergolong dapat diterima ( rentang 0-150 ms), dan nilai packet loss tergolong bagus $<1 \%$ dan nilai throughput menunjukan rata-rata paket yang diterima.

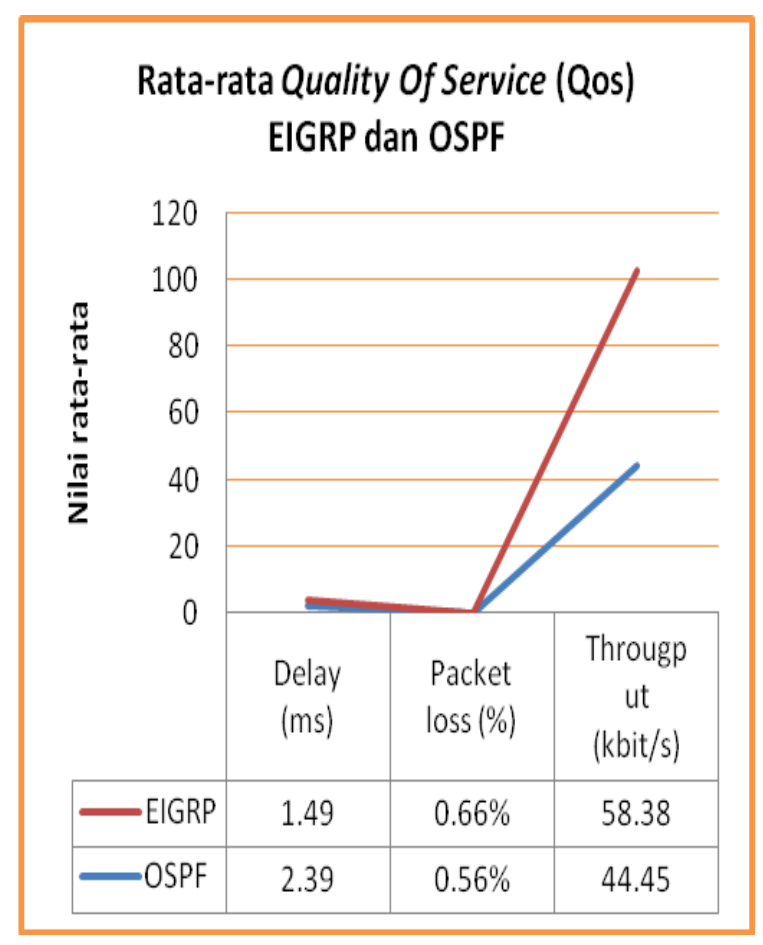

Gambar 10. Grafik Qos EIGRP dan OSPF

Berdasarkan grafik pada gambar 10, Qos EIGRP dan OSPF di atas diketahui rata-rata delay pada pada EIGRP sebesar $1,49 \mathrm{~ms}<2,39 \mathrm{~ms}$ pada OSPF, disimpulkan bahwa nilai delay keduanya masih dapat diterima. Rata-rata nilai packetloss pada EIGRP $0,66 \%>0,56 \%$ pada OSPF, besaran packetloos mempengaruhi kinerja jaringan menjadi jelek oleh karena itu hasil tersebut pada keduanya masih tergolong baik. Sedangkan pada throughput diperoleh EIGRP 58,38bit/s dan OSPF 44,45bit/s. Nilai pada throughput menunjukan banyak jumlah paket rata-rata yang diterima pada EIGRP dari pada OSPF. Berdasarkan analisis Qos secara keseluruhan pada EIGRP dan OSPF disimpulkan keduanya memiliki Qos yang seimbang dalam kinerjanya. 


\section{Simpulan dan saran}

Berdasarkan hasil percobaan simulasi routing protocol EIGRP dan OSPF menggunakan 6 router diperoleh pada tabel routing EIGRP dan OSPF dengan nilai AD dan matric yang lebih kecil adalah EIGRP oleh karena itu EIGRP lebih baik dalam dalam pemilihan jalur. Pada routing protocol EIGRP dan OSPF diperoleh rata-rata waktu yang digunakan dengan traceroute dengan 5 kali peroleh EIGRP adalah 73,6 ms dan OSPF sebesar 76,8 ms. Disimpulkan bahwa nilai EIGRP lebih kecil waktu tansfer data maka perpindahan data nya lebih cepat. Pada routing protocol EIGRP dan OSPF di peroleh rata-rata Quality Of Service (Qos) meliputi delay, packetloss dan throughput, yakni rata-rata delay pada pada EIGRP sebesar $1,49 \mathrm{~ms}$ dan OSPF sebesar 2,39 ms. Sehingga delay EIGRP lebih baik. Rata-rata nilai packetloss pada EIGRP $0,66 \%$ dan pada OSPF 0,56 \%. Sehingga packetloss OSPF lebih baik. Rata-rata throughput diperoleh EIGRP 58,38bit/s dan OSPF 44,45 bit/s. Sehingga throughput EIGRP lebih baik. Secara keseluruhan Quality Of Service (Qos) pada EIGRP dan OSPF seimbang dalam kinerjanya. Berdasarkan analisis secara peformance disimpulkan bahwa routing protokol EIGRP lebih baik dari pada OSPF.

Adapun saran dalam penelitian ini untuk melakukan percobaan dengan menggunakan router yang lebih banyak dan topologi yang lebih besar. Dalam penelitian ini pengujian masih menggunakan delay, packet loss, dan throughput, maka dapat menambah parameter yang diamati tentang peformance dan Quality of Service (Qos). Percobaan ini menggunakan laptop yang di pengaruhi oleh kecepatan prosessor, jadi kecepatan jaringan juga berpengaruh pada penelitian ini oleh karena itu peneliti selanjutnya dapat menggunakan perangkat komputer dengan kecepatan prosessor yang besar. Selain itu dalam pada simulasi yang dilakukan masih menggunakan simulator GNS 3, maka berikutnya dapat menggunakan router dalam bentuk real hingga memperoleh hasil yang relevan dan akurat.

\section{Daftar Rujukan}

Anonim. 2012. "Routing OSPF" https://www.braincert.com/tutorial/Routing-OSPF (diakses pada tanggal 5 september 2015).

Febri, U., dan Naemah, M., 2014. Analisis Kinerja Routing Dinamis Dengan Teknik RIP Pada Topologi Ring Menggunakan Jaringan LAN menggunakan Cisco Tracer, Journal Singuda Ensikom, volume 7.

Ferguson, P. \& Huston, G. 1998. Quality of Service. John Wiley \& Sons Inc.

Kurniawan, W. 2007. Jaringan Komputer. Semarang: Andi.

Lammle, T. 2005. CCNA Cisco Certified Network Associate Study Guide. Cetakan I. Terjemahan S'to, CCNA, MCSE. Jakarta: PT. Elex Media Komputindo.

Lin, Y.D., Hwang R.H., Baker, F., 2012. Computer Network An Open Source Approuch. McGraw - Hill International Edition.

Munir.M.T. 2009. Pembelajaran Jarak Jauh Berbasis Teknologi Informasi dan Komunikasi. Bandung: Alfabeta.

Putri,E.K., Anggun,F, dan Alfin, H. 2014. Analisis Qos pada jaringan multi protocol label switching (MPLS) studi kasus di pelabuhan indonesia cabang tanjung intan cilacap, Journal.2014 Http://www.Academia.Edu/10258365/Analisis_Qos_Pada_Jaringan_Multi. (diakses pada tanggal 5 september 2016).

Ramdhani, S,. Lina, O., dan Ery,S. 2015. Analisis Perbandingan Kinerja Routing RIV EIGRP dan OSPF di PT.Chevron Pacific, Journal JomFTEKNIK, volume 2, 2015.

Resnu ,K.L.,.2015. Analisis Quality of service video streaming berbasis web, Journal.

Sofana, I., 2008. Membangun JaringanKomputer, Membuat jaringan Komputer (Wire \& Wireless) Untuk Pengguna Windows dan Linux. Informatika: Bandung.

Sofana, I. 2012. “Cisco CCNA Dan Jaringan Komputer”. Informatika: Bandung. 